Family Profile No. 24, 2020

\title{
Marriage Rate in the U.S.: Geographic Variation, 2019
}

Author: Leslie Reynolds

This Family Profile, an update of previous profiles on the marriage rate [FP-17-25; FP-18-20; FP-19-22], estimates adjusted marriage rates for the U.S. and each state for 2019. Using American Community Survey (ACS) data, we estimate the number of marriages occurring in the last year among unmarried women, calculate the margins of error, and describe geographic variation. For detailed information on the adjusted marriage rate from 2008-2017, see "Charting Marriage \& Divorce in the U.S.: The Adjusted Marriage Rate" (Payne, 2018).

\section{U.S. Marriage Rate, $\mathbf{2 0 1 9 ^ { 1 }}$}

- The marriage rate continued to be stable in 2019, remaining at a 45-year low since 2010.

- In 2019, there were 30.5 marriages per 1,000 unmarried women.

- 2.2 million women married in 2019, an increase of about 117,742 marriages from 2010.

${ }^{1}$ Rates are represented as the number of women aged 15 or older who married in the past year per 1,000 unmarried women aged 15 or older

\section{Five Highest and Lowest Marriage Rates, 2019}

- Wyoming (surpassing Utah) now holds the top spot in terms of the marriage rate with 49 marriages per 1,000 unmarried women in 2019.

- Rhode Island continues to hold the lowest marriage rate in 2019. The rate decreased from 24 marriages per 1,000 unmarried women in 2018 (FP-19-22) to 21 Data Sources: marriages per 1,000 unmarried women in 2019.

Clarke. S. C. (1995). Advanced report of final marriage statistics, 1989 and 1990. Monthly Vital Statistics Report, 42(12). National Center for Health Statistics. https://www.cdc.gov/nchs/data/mvsr/supp/mv43_12s.pdf

National Center for Health Statistics (1974). Summary report final marriage statistics, 1970. Monthly Vital Statistics Report, 23(2), Supp.1. U.S. Department of Health, Education, and Welfare. https://www.cdc.gov/nchs/data/mvsr/supp/mv23_02s1acc.pdf National Center for Health Statistics (1983). Advance report of final marriage statistics, 1980. Monthly Vital Statistics Report, 32(5), Supp. U.S. Department of Health and Human Services. https://www.cdc.gov/nchs/data/mvsr/supp/mv32_05s.pdf

National Center for Health Statistics (2001). Births, marriages, divorces, and deaths: Provisional data for January-December, 2000. National Vital Statistics Report, 49(6), Associated Table 3. Department of Health \& Human Services, Center for Disease Control and Prevention. https://www.cdc.gov/nchs/data/nvsr/nvsr49/nvsr49_06.pdf

U.S. Census Bureau (2020). American Community Survey, 2019 1-Year Estimates [Table B12001]. Retrieved from:

https://data.census.gov/cedsci/table?q=B12001\&lastDisplayedRow=18\&table=B1200 $1 \&$ tid=ACSDT1Y2019.B12001

U.S. Census Bureau (2020). American Community Survey, 2019 1-Year Estimates [Table B12501]. Retrieved from:

https://data.census.gov/cedsci/table?q=B12501\&lastDisplayedRow=10\&table=B1250 1\&tid=ACSDT1Y2019.B12501

Figure 1. Women's Adjusted Marriage Rate, 1970-2019

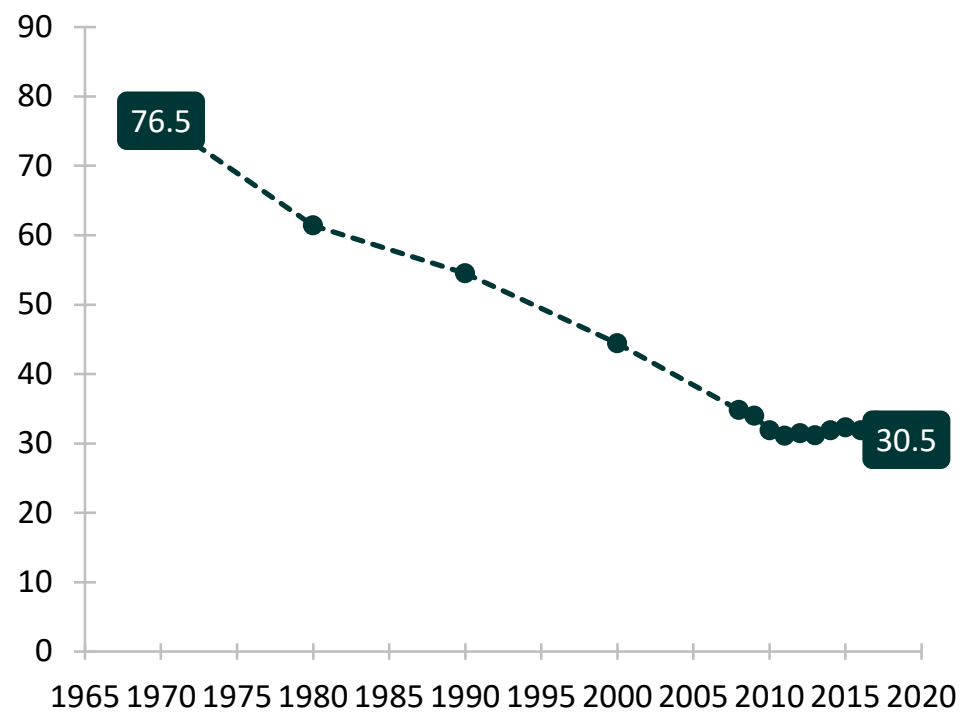

Source: NCFMR analyses of 1970-2000, National Center for Health Statistics; 2008-2019, U.S. Census Bureau, American Community Survey, 1-yr est.

Figure 2. Women's Highest and Lowest Marriage Rates

\begin{tabular}{|l|lll|}
\hline Rank \& State & Marriage Rate & MOE $^{2}$ \\
\hline 1. Wyoming & 49.5 & $+/-$ & 11.3 \\
2. Utah & 45.3 & $+/-$ & 4.1 \\
3. Colorado & 42.0 & $+/-$ & 3.3 \\
4. Washington & 41.3 & $+/-$ & 3.1 \\
5. Idaho & 40.6 & $+/-$ & 6.6 \\
USA & 30.5 & $+/-$ & 0.4 \\
47. Louisiana & 24.4 & $+/-$ & 3.1 \\
48. Vermont & 23.9 & $+/-$ & 4.7 \\
49. Connecticut & 22.7 & $+/-$ & 2.9 \\
50. Delaware & 21.5 & $+/-$ & 4.8 \\
51. Rhode Island & 21.3 & $+/-$ & 5.1 \\
\hline
\end{tabular}

Source: NCFMR analyses of U.S. Census Bureau, American Community Survey, 2019 1-yr est.

${ }^{2} \mathrm{MOE}=$ Margin of Error. The MOE is a measure of sampling error and expresses the maximum range in which the rate is expected to differ from the actual proportion. The MOE is calculated for the derived estimates at the $90 \%$ confidence level. 


\section{State Rankings and Geographic Variation in Marriage Rates, 2019}

Figure 3. State Variation in the Adjusted Marriage Rate per 1,000 Unmarried Women Aged 15+ by Quartile, 2019

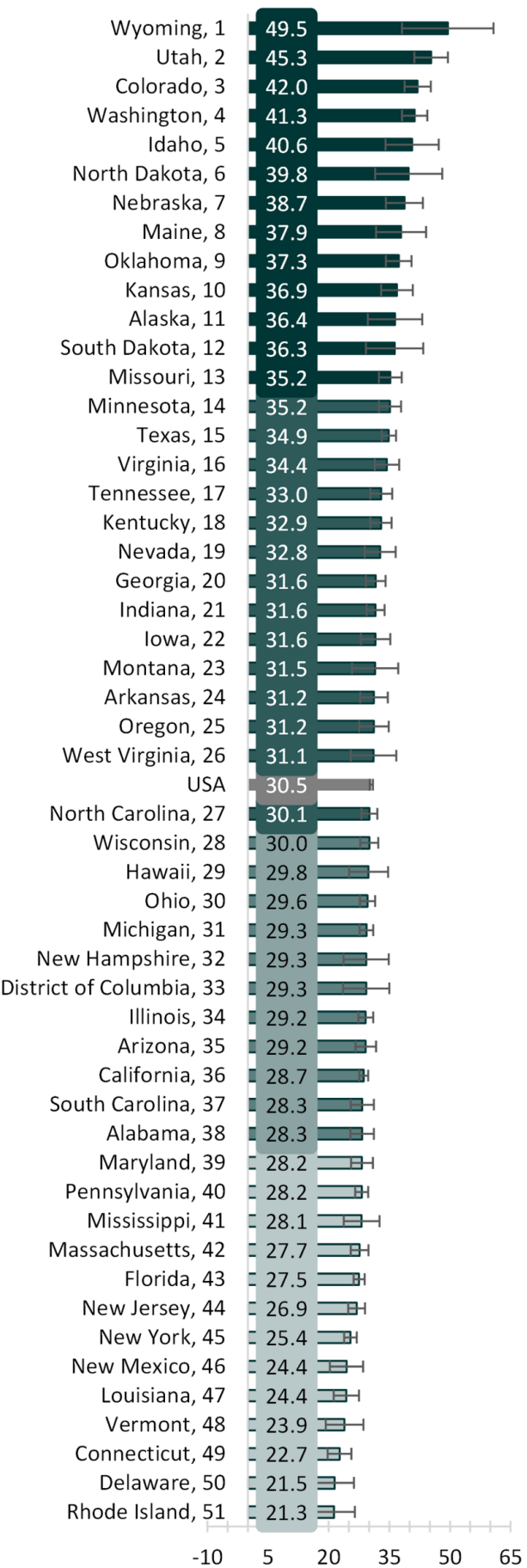

Source: NCFMR analyses of U.S. Census Bureau, American Community Survey, 2019 1-yr est.
- The states with the highest marriage rates (making up the 1st quartile) in 2019 had rates of at least 35.2 marriages per 1,000 unmarried women aged 15 and older. Among the states in the top quartile, all are substantially above the national average (30.5 marriages per 1,000 unmarried women).

- The states with the lowest marriage rates (making up the 4th quartile) in 2019 had fewer than 28.2 marriages per 1,000 unmarried women. Among the states in the bottom quartile, those with marriage rates considerably below the national average are Rhode Island, Delaware, Connecticut, Vermont, Louisiana, New Mexico, New Jersey, New York, Florida, Massachusetts, Mississippi, Pennsylvania, and Maryland.

Figure 4. Geographic Variation of Women's Adjusted Marriage Rate Among States, 2019

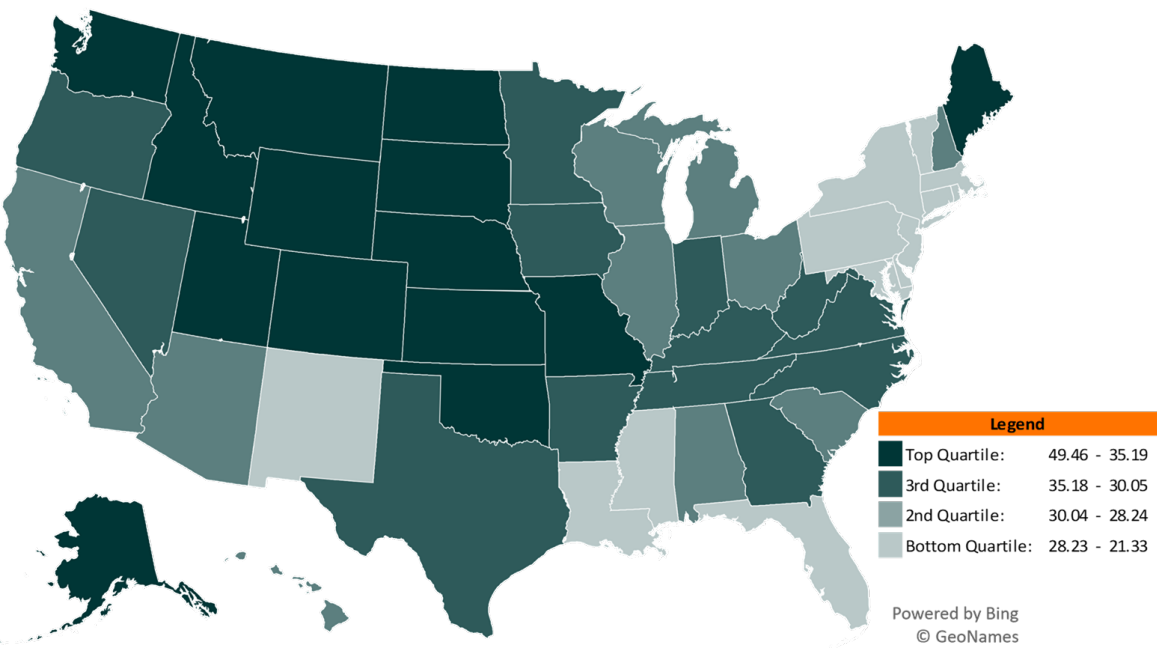

Source: NCFMR analyses of U.S. Census Bureau, American Community Survey, 2019 1-yr est.

- Most states in the Western region of the country had high marriages rates (1st or 2nd quartile).

- Exceptions include California, Arizona, and New Mexico.

- Midwestern states exhibited marriage rates in the top three quartiles with the largest share found in the first.

- Southern states are spread across each quartile. The largest share is found in the second.

- All states in the Northeast (except for Maine) exhibited low marriage rates (3rd or 4 th quartile).

References:

Allred, C. (2019). Marriage rate in the U.S.: Geographic variation, 2018. Family Profiles, FP-19-22. Bowling Green, $\mathrm{OH}$ : National Center for Family \& Marriage Research. https://doi.org/10.25035/ncfmr/fp-19-22.

Hemez, P. (2017). Marriage rate in the U.S.: Geographic variation, 2016. Family Profiles, FP-17-25. Bowling Green, OH: National Center for Family \& Marriage Research. https://doi.org/10.25035/ncfmr/fp-17-25

Payne, K. K. (2018). Charting marriage and divorce in the U.S.: The adjusted divorce rate. Bowling Green, OH: National Center for Family \& Marriage Research. https://doi.org/10.25035/ncfmr/adr-2008-2017

\section{Suggested Citation:}

Reynolds, L. (2020). Marriage rate in the U.S.: Geographic variation, 2019. Family Profiles, FP-20-24. Bowling Green, OH: National Center for Family \& Marriage Research. https://doi.org/10.25035/ncfmr/fp-20-24

http://www.bgsu.edu/ncfmr ncfmr@bgsu.edu (419) 372-3119 